\title{
Interactive comment on "Effects of global ship emissions on European air pollution levels" by Jan Eiof Jonson et al.
}

Jan Eiof Jonson et al.

j.e.jonson@met.no

Received and published: 1 July 2020

We, the authors, thank the reviewers for constructive comments and suggestions.

Below we list the comments from reviewer 1 followed by our reply with references to changes made in the paper.

Comments to remarks from reviewer 2 
Specific comments 1:

Globally the highest $d(P M)$ concentrations are calculated over parts of Asia and North Africa. Authors have not cited any regional results in East Asia or North Africa, or observation. A comparison on the results for regional level is necessary. At least, Fig $2 b$ shows significant underestimation in China (please refer to: "Impacts of shipping emissions on PM2.5 pollution in China. Atmospheric Chemistry and Physics 2018, 18, 15811-15824)".

Reply:

The contribution of ships to annual average PM2.5 in Lv et al (2018) is around 3$5 \mu \mathrm{gm}^{-3}$ around Shanghai (Fig 3a of Lv (2018)). This is higher, but roughly comparable to our estimate of shipping contribution, which is $2-3 \mu \mathrm{gm}^{-3}$ for the same area. The spatial patterns of 0.1 microgram per cubic meter concentration contour line from shipping are also similar. There can be several reasons for differences, e.g use of different emission inventories, atmospheric models and weather data. Regardless, both studies are fairly consistent of shipping contribution to PM2.5 concentration over this area. Several factors that can cause differences are listed below:

- First, our study uses STEAM3 emission inventories which are based on the modelling of individual ships and their engines. In STEAM, fuel type assignment is done based on engine characteristics which differs from the Liu et al approach, who seemed to assume OGVs always using HSHFO. This difference is likely to be small because most of the large ships operating in this area use 2-stroke main engines for propulsion, with the exception of cruise vessels which often rely on 4-stroke MSDs.

Printer-friendly version

- The second obvious difference comes with the activity data. Lv et al use 2013 as a base year of shipping activity, whereas our study describes year 2017. It is likely that during this time vessel activity has increased because of a recovery of

Interactive

comment

C2 
the economy after the 2008 financial crisis.

- A third difference is the activity source itself. The current work is based on the combination of satellite and terrestrial AIS data provided by Orbcomm Ltd, whereas $L v$ et al do not state their data source, but this is most likely higher update rate AIS from Chinese national network than the Orbcomm data used in this work.

- A fourth difference which could explain the lower shipping contribution in the Shanghai area is the inclusion of low sulphur emission zones (Pearl river Delta, Bohai Sea and Yangtze river delta) which is included in the STEAM3 inventories. Since $L v$ et al concentrate on 2013 emissions, this emission reduction did not exist at that time. This will cut PM emissions easily by $50 \%$, reducing the PM total emissions from ships.

- The regional model calculations of $L v$ et al. used a finer model resolution than in our study (36 $\times 36 \mathrm{~km}$ versus $0.5 \times 0.5$ degrees). A finer resolution may result in higher peak concentrations.

In our view, our results of PM shipping contribution to air quality are in agreement with the earlier work of Lv et al. (2019) both in spatial pattern and in magnitude.

We have included a reference to the $L v$ et al. (2018) paper in the Introduction:

With ship emissions representative for year 2013, Lv et al. (2018) calculated contributions from ship emissions to $\mathrm{PM}_{2.5}$ concentrations of up to $5.2 \mu \mathrm{gm}^{-3}$ in coastal regions in China, higher than in European coastal regions. Since 2013 emission controls have been imposed in several steps, Âă limiting the sulfur content in marine fuels to $0.5 \%$ in several Chinese ports and territorial waters. 
And in the conclusions:

In Chinese coastal regions the contributions to $\mathrm{PM}_{2.5}$ concentrations in this study are lower than in the study by $L v$ et al. (2018). There are several possible explanations for this difference. Lv et al. (2018) used a finer model resolution $(36 \times 36 \mathrm{~km})$ than in the present study. A finer resolution is likely to result in somewhat higher peak concentrations. Stricter regulations, limiting the sulfur content in marine fuels to $0.5 \%$ in and around several Chinese ports, including the YRD (Yangtze River Delta), have been imposed between these two studies (2013 versus 2017), and are included in the ECCAD 2017 ship emissions. According to Lv et al. (2018) YRD is responsible for about $20 \%$ of the ship emissions in Chinese waters.

\section{Specific comments 2:}

I don't understand the logic for ozone part, specifically Fig. 5. The ratio between NOx and NMVOC, which determine the ozone titration of formation, is for the receptor instead of source. How can Fig. 5 present opposite effects in the same receptor region, same season by different source regions' shipping emissions? Same problem for Fig.6. The only explanation is that ozone was transported instead of the precursors. If so, the way authors discuss the issue in section 3.2 should be revised to focus on the ozone transportation. Then another question comes, if the ozone titration happens in where the emissions were released, does the model show ozone reduction in the emission region as well? Anyway, ozone transportation related analysis needs to be conducted. Current version could not provide full support for results.

Reply:

We now explain this in the first part of section 3. as follows:

Below we include the model results from all ship emissions, and from ship emissions in separate sea areas based on the model scenarios listed in Table 2, For the calculations perturbing the emissions in separate sea areas, the total effect in a receptor area will then be the sum of contributions from all the individual sea areas. This sum will then

Printer-friendly version

Discussion paper 
be a combination of the emission and chemical production/destruction of the species within the source sea area, and production/destruction of the species elsewhere (including the receptor region). Similar positive and negative contributions was also shown in the TF_HTAP2 model experiment, exemplified by the results in Jonson et al. (2019) and in the EMEP source receptor calculations, exemplified by EMEP, (2019), appendix $C$. Thus, for example, reductions in the receptor area can be caused by chemical reactions that only occur in the source area (e.g. ozone titration), followed by transport of a smaller amount of the species (e.g. ozone) into the target area.

\section{Specific comments 3:}

SR (Source Receptor) calculations are not described very clearly. How to determine the $100 \%$ of the effects of source contribution by $15 \%$ reduced source emissions? If $10 \%$ or $20 \%$ were chose, will the source contribution (100\%) be different?

Reply:

This is discussed in section 2.3. In In Table 5 and 6 the depositions from shipping are scaled by 100/15. This scaling is made in Figure 2, right panes and in Figure 3 and 5. This information was unfortunately missing in the original submission.

Non-linearities are not a model uncertainty. The contribution of one source area depends on contributions from other source areas. This complication also applies to other source receptor methods, e.g. tagging methods or adjoint methods. Also in the real world, if one was able to switch off one source at a time (100\% reduction), and do this for all sources, one after another (and measure each increment individually), then the sum of all individual increments would be different from the total concentration in the receptor area. This is due to the non-linearity of atmospheric chemistry. The choice of $15 \%$ was made for reasons explained in the manuscript. 'Contributions' calculated in this way should be seen as a measure of what can be achieved by emission reductions of this order of magnitude in the source areas.

In section 2.3 we now include the following: 
Reducing the emissions by a different percentage would give different results depending on species and location. The choice of $15 \%$ is partially political as reductions of this magnitude are achievable within a timeframe of a few years and at the same time give a large enough signal when processing the model output.

Specific comment 4:

Interactive

comment

Pseudo-species "ShipNOx" also needs further explanation. 50\% as shipNOx, then how about other $50 \%$ ? In this $50 \%$, how much will go to R1 and how much for R2?

Reply;

We now specify that the remaining $50 \%$ is emitted as NO and NO2 as in the Base model runs (for shipping 95\% as NO). To trace how much will go through R1 and how much through $R 2$ is not possible with the present model setup.

\section{Specific comment 5:}

The connections with authors' previous paper of "Effects of strengthening the BalticSea ECA regulations" need to be built. Are the 2016 and 2017 results comparable in Baltic Sea region? Any differences? Connections on scenarios.

Reply:

We have included a reference to the 2019 paper in the introduction, and also to the companion paper Barregaard et al. (2019). In both the 2019 paper and the present paper we use the EMEP model, but with different model domain and model resolution. In both studies ship emissions from FMI and land based emissions from Eclipse are used. Model results are comparable in these two studies bearing mind that the meteorological year is different and that model perturbations are only made for the Baltic Sea.

Specific comment 6: Line 214-217. The well-known mechanisms explained here were not connected to the specific findings in either text or figures. So what? Any nitrate 
Specific comment 7:

No speciation was provided for PM2.5. Thus, the talking ammonia, nitrate or sulfate was not supported well, which also linked to question 6.

Reply:

In addition to the figure showing the fraction of sulfate in PM2.5, we have now included figures showing the corresponding fractions of nitrate, primary particles and ammonium. As now mentioned in the paper, ship emissions will result in the formation of sodium nitrate particles, but these are generally large particles not contributing to PM2.5. Thus the seasonal variation of nitrate shown in Figure 3 is a result of ammonium nitrate.

Interactive comment on Atmos. Chem. Phys. Discuss., https://doi.org/10.5194/acp-2020-293, 2020. 